\title{
Words in action: Examining what clinical education placement documents contribute to thinking, acting and feeling like a health professional
}

\author{
L. Furness ${ }^{1,2,3,4}$, J. Ostini ${ }^{1} \nLeftarrow$ $A$. Tynan ${ }^{1,2,5}$
}

\begin{abstract}
Introduction: Clinical placements are critical for student learning and transition to practice. They help students integrate their knowledge and skills and support their development of professional identity—so they come to "think, act and feel" like a member of their profession. Students have reported that placements play a role in development of professional identity. Documents are frequently the first contact students have with the placement setting. However, there are few studies examining the impact of clinical placement documents on the development of allied health students' professional identity. This study examines what clinical placement documents contribute to the development of professional identity through facilitating thinking, feeling and acting like a health professional.

Methods: Thematic analysis of clinical education placement documents was conducted using a deductive framework based on review of literature considering how students can be supported to think, act and feel like a health professional.

Results: Thirteen placement orientation documents were reviewed. Reference to factors that support "thinking" described learning opportunities to enable students to develop knowledge for practice. Reference to factors that support "acting" described graded learning that enables student contribution to service delivery and recognition as a health professional, and reference to factors that support "feeling" described workplace culture and practices supporting connectedness.
\end{abstract}

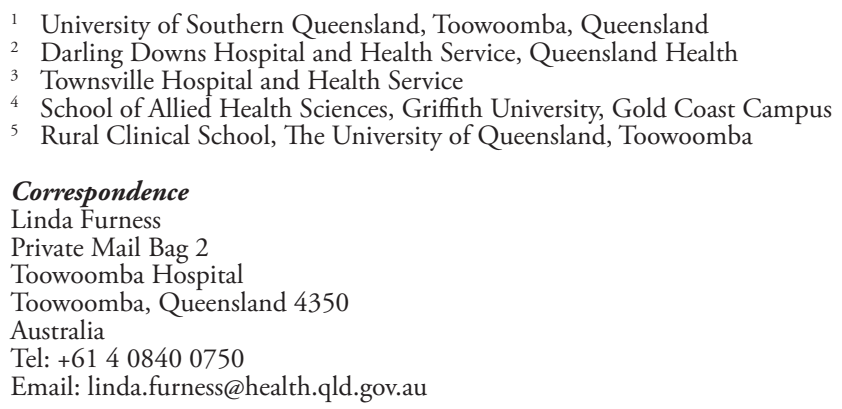


WORDS IN ACTION

Conclusions: This study identified that placement documents can contribute to allied health students thinking, acting and feeling like a health professional while on clinical placement. Academic staff and organisations reviewing clinical placement documents may wish to consider the implications identified in this study, which demonstrate how documents can include or exclude students in the workplace.

Keywords: clinical education; clinical placement; allied health; professional identity; rural and regional

\section{Introduction}

Professional identity formation has been written about by many authors (Cruess et al., 2014, 2015a, 2015b; Frost \& Regehr, 2013; Holden, Buck, Clark et al., 2012; Holden, Buck, Luk et al., 2015; Li et al., 2009; Monrouxe \& Poole, 2013; Sharpless et al., 2015; Wald, 2015; Weaver et al., 2011). Although a number of conceptual frameworks illustrating professional identity development are found in medical education literature, consensus has not been reached on the most effective approach to examining professional identity development (Cruess \& Cruess, 2016; Cruess et al., 2015b; Mylrea et al., 2017; Vivekananda-Schmidt et al., 2015; Wald, 2015). Frameworks describing professional identity development draw on a number of theories, including role theory, and consider identity development as both a personal and social process (Hercelinskyj et al., 2014).

Merton (1957) argued that the purpose of medical education is:

to shape the novice into the effective practitioner of medicine, to give him [sic] the best available knowledge and skills, and to provide him [sic] with a professional identity so that he $[$ sic $]$ comes to think, act and feel like a physician. (p. 7)

Merton's definition of professional identity has continued to be used in medical education research (Cruess et al., 2014). More recently, Mylrea et al. (2017) drew on the work of Merton to explore the role of self-determination theory in the development of professional identity for pharmacy students. Mylrea et al. proposed that self-determination theory can explain how beginning to think, act and feel like a health professional facilitates the development of students' professional identity. They developed a conceptualisation of professional identity, suggesting the self-determination theory elements of competence, relatedness and autonomy may facilitate professional identity development by assisting students to "think, act and feel like a health professional" (p. 7).

During clinical placements, students are supported to develop competencies related to their profession (Mylrea et al., 2017). The element of "thinking" identifies students' need to be effective in dealing with the workplace environment through knowledge and skill development (Mylrea et al., 2017). "Acting", or autonomy, considers how students are supported to explore, take initiative and develop and implement solutions for service delivery (Dall'Alba, 2009; Mylrea et al., 2017; Nicola-Richmond et al., 2016). During workplace learning on placement, students have contact with members of their own profession (Cruess et al., 2014; Wald, 2015; Wilson et al., 2013), members of other professions (Wald, 2015; Weaver et al., 2011) and patients and their families 
(Jaye \& Egan, 2006; Ó Lúanaigh, 2015; Wald, 2015). This socialisation and these relationships are included in the "feeling" element and can influence the adoption of professional values and identity development (Cruess et al., 2014; Ó Lúanaigh, 2015; Wald, 2015; Weaver et al., 2011; Wilson et al., 2013).

Clinical education documents are frequently used for student placement, and significant time is often invested in their development and update. These documents are also typically the first contact students have with a placement environment (when their placements are confirmed) and later underpin orientation (when students commence placement). Minimal attention has been given to how clinical education documents may contribute to thinking, acting and feeling like a health professional. The aim of this study is to examine clinical education documents and explore how they may contribute to thinking, acting and feeling like a health professional. Better understanding of the influence of clinical placement documents in supporting learning and development of professional competencies and connectedness in the workplace can support safe and effective patient care through a more effective transition to practice.

This project forms part of a larger qualitative study exploring the impact of clinical placement on development of allied health student professional identity. The overall project investigates perspectives of allied health staff and students and organisational influences on the development of professional identity (Furness et al., 2019).

\section{Methods}

Ethical approval for the project as a whole was received from the health service and affiliated university ethics committees, and the research was conducted in accordance with National Health and Medical Research Council (NHMRC) National Statement on Ethical Conduct in Human Research guidelines. The research team comprised individuals with backgrounds in research methodology, clinical education and communication.

\section{Setting}

This study was conducted in a rural and regional public health service in Queensland, Australia. The health service is comprised of one regional hospital and six rural hospitals, which provide pre-registration clinical placements to allied health students. Allied health clinical placements are coordinated and supported by the clinical education support officer for each profession (McBride et al., 2015). The allied health professions grouped together in the health service organisational structure were included in this study. The professions of nutrition and dietetics, occupational therapy, physiotherapy, psychology, social work and speech pathology were the focus of the study. Within this health service, clinical education is considered part of core business, and key performance indicators are reported to the health service executive. The primary researcher (LF) works in a clinical education support officer role in the health service and holds the dual roles of worker and insider-researcher (Workman, 2007). 
WORDS IN ACTION

\section{Study design}

A qualitative description approach was utilised to explore what clinical placement documents contribute to thinking, acting and feeling like a health professional (Bradshaw et al., 2017). This approach provided opportunity to use a rich description of the data and interpret findings without moving too far from the literal description of the data (Bradshaw et al., 2017). A document review approach was chosen to analyse documents that contained information on the context in which students were completing their placement (Bowen, 2009). Advantages of document review relevant to this study were cost minimisation, efficiency in accessing readily available documents with a lack of obtrusiveness (Bowen, 2009) and reliability, as documents were in existence before they were used as part of the research (Miller \& Alvarado, 2005).

This document review was based on the process described by O'Leary (2007). The process involved creating a list of documents to be reviewed, obtaining electronic copies of the documents, reviewing documents using the deductive framework and analysing data in themes. A purposive sampling strategy was used to locate and access relevant documents (Miller \& Alvarado, 2005). Emails requesting copies of clinical placement orientation documents currently in use were sent by the primary researcher to clinical education support officers in October 2018 (refer to Table 1 for inclusion/exclusion criteria). To ensure data was comprehensive, the primary researcher spoke with each clinical education support officer to clarify inclusion/exclusion criteria and provide opportunities for clarification about requested documents.

Deductive thematic analysis of the documents was conducted using the steps outlined by Braun and Clarke (2006). Steps used for thematic analysis were: 1) familiarisation with the data through repeated reading of documents, 2) coding documents using the think/act/feel framework, 3) identifying data supporting themes, 4) reviewing themes, 5) naming themes and, finally, 6) writing up the study. The deductive coding framework for thematic analysis was developed by the authors, drawn from review of literature examining the development of professional identity for health professionals.

\section{Table 1}

\section{Document Review Inclusion/Exclusion Criteria}

\begin{tabular}{|c|c|}
\hline Inclusion & Exclusion \\
\hline $\begin{array}{l}\text { - Documents used in the allied health professions of } \\
\text { physiotherapy, psychology, occupational therapy, } \\
\text { speech pathology, social work, nutrition and dietetics } \\
\text { - Health service documents for student welcome, } \\
\text { information, orientation and health service student } \\
\text { handbooks } \\
\text { - Documents developed by Queensland Health state- } \\
\text { wide clinical education programs adapted for health } \\
\text { service context } \\
\text { - Handbooks, PowerPoint orientation presentations, } \\
\text { orientation handbooks } \\
\text { - Documents in current use }\end{array}$ & $\begin{array}{l}\text { - University produced documents including subject } \\
\text { handbooks, practice placement handbooks and } \\
\text { manuals, placement competency assessment tools } \\
\text { - Documents not in current use } \\
\text { - Documents from other health professions (e.g., } \\
\text { medicine, nursing, other allied health professions) }\end{array}$ \\
\hline
\end{tabular}


WORDS IN ACTION

The coding framework was piloted in other components of the overall study to analyse focus group discussions with students and staff (Furness et al., 2019, 2020). The "thinking" code identified references to supporting student skill development for competence; the "acting" code identified references to development of independence and service provision as an autonomous health professional; the "feeling" code identified references to relatedness and connectedness in the workplace. Coding was completed by the primary author and reviewed by others in the research team. Differences were resolved by discussions within the research team.

\section{Results}

Thirteen organisational documents (student orientation folders, orientation presentations, student handbooks) were examined (refer to Table 2 for details of documents reviewed). Five out of 13 documents were adapted from state-wide clinical education program documents by health service clinical education support officers. The remaining documents were developed within the health service.

\section{Thematic analysis: Contributing to thinking, acting and feeling like a bealth professional}

Clinical education documents all referenced implicitly or explicitly how placements support students to think, act and feel like a health professional. References in documents to factors that support thinking like a health professional described learning opportunities during placement that support students to develop knowledge for practice. Acting described actions for gaining independence and autonomy in working with patients and recognition as a health professional, and feeling described workplace culture and practices supporting connectedness. An overview of themes is shown in Table 3 .

\section{Thinking supported by learning opportunities}

The thinking theme identified learning opportunities that were supported by clinical educator collaboration and learning through working with patients and members of the students' own and other professions. For students to begin to think, act and feel like a member of their profession, they needed to demonstrate underpinning competencies identified by the profession. Competency assessment was described in orientation manuals:

The assessment methodology used by students will correspond to their particular university curriculum. Formal assessment will be conducted at mid-unit and end-unit using the APP [Assessment of Physiotherapy Practice] Student Assessment Tool. (Darling Downs Hospital and Health Service, 2016, p. 5) 
WORDS IN ACTION

\section{Table 2}

\section{Documents Reviewed}

\begin{tabular}{|c|c|c|c|c|}
\hline \multirow[t]{2}{*}{ Document Reviewed } & \multirow[t]{2}{*}{ Authorship } & \multicolumn{3}{|c|}{ Thematic Mapping } \\
\hline & & Think & Feel & Act \\
\hline $\begin{array}{l}\text { Allied Health Clinical Education: Darling Downs Health } \\
\text { Values for Students (All allied health professions) }\end{array}$ & Health service & $x$ & $\mathrm{x}$ & $\mathrm{x}$ \\
\hline $\begin{array}{l}\text { Downs Health Speech Pathology } \\
\text { Student Orientation Manual }\end{array}$ & Health service & $x$ & $x$ & $x$ \\
\hline $\begin{array}{l}\text { Darling Downs Health Toowoomba Physiotherapy } \\
\text { Department Student Orientation Manual }\end{array}$ & Health service & $x$ & $x$ & $x$ \\
\hline Darling Downs Health Psychology Student Orientation & Health service & $x$ & & $x$ \\
\hline $\begin{array}{l}\text { Psychology "Ready Set Go" orientation presentations } \\
\text { and fact sheets: } \\
\text { - Confidentitality } \\
\text { - Documentation } \\
\text { - Multidisciplinary team } \\
\text { - Supervision } \\
\text { - Making the most of placement } \\
\text { - Self care }\end{array}$ & Health service & $x$ & $x$ & $x$ \\
\hline $\begin{array}{l}\text { Darling Downs Health Western Cluster Allied Health } \\
\text { Dietetics Pre-Placement Pack }\end{array}$ & Health service & & $x$ & $x$ \\
\hline $\begin{array}{l}\text { Nutrition and Dietetics Student Induction Manual } \\
\text { Darling Downs Health }\end{array}$ & Health service & $x$ & $x$ & \\
\hline Student welcome email template (nutrition and dietetics) & Health service & $x$ & & \\
\hline Placement confirmation letter template (social work) & Adapted from state document & $x$ & $x$ & $x$ \\
\hline $\begin{array}{l}\text { Onboarding } 2017 \text { student orientation presentation } \\
\text { (social work) }\end{array}$ & Adapted from state document & $x$ & $x$ & \\
\hline Student welcome email template (occupational therapy) & Adapted from state document & $x$ & $x$ & \\
\hline $\begin{array}{l}\text { Student Practice Placement Handbook (occupational } \\
\text { therapy) }\end{array}$ & Adapted from state document & $x$ & $x$ & $x$ \\
\hline $\begin{array}{l}\text { Occupational Therapy Student Orientation PowerPoint } \\
\text { presentation }\end{array}$ & Adapted from state document & $x$ & $x$ & $x$ \\
\hline
\end{tabular}

Source: Developed for this research based on Miles and Huberman (1994)

Competency assessment was also implied:

Students are expected to familiarise themselves with SPEF-R [Student Review of Professional Practice Placement [C] assessment tool and clarify with Clinical Educator how the domains could be demonstrated in the specific practice placement setting. (Occupational Therapy Clinical Education Program, 2018, p. 8).

The Psychology Clinical Practicum Competencies Rating Scale explicitly stated that students must work collaboratively with their supervisor/clinical educator and accept supervisory input in order to develop competencies (The University of Queensland, n.d.). Other documents, such as the social work orientation documents (Darling Downs 
WORDS IN ACTION

\section{Table 3}

What Documents Contribute to Facilitating Thinking, Acting and Feeling as a Health Professional

\begin{tabular}{|c|c|}
\hline Framework Element & Themes \\
\hline Think & $\begin{array}{l}\text { - Learning supported by clinical educator collaboration } \\
\text { and relationship } \\
\text { - Learning through working with patients, members of } \\
\text { own and other professions }\end{array}$ \\
\hline Act & $\begin{array}{l}\text { - Graded learning under clinical educator supervision } \\
\text { - Contribution to service delivery } \\
\text { - Recognition as a health professional }\end{array}$ \\
\hline Feel & $\begin{array}{l}\text { - Culture/attitude of workplace } \\
\text { - Connections in the workplace } \\
\text { - The country vibe }\end{array}$ \\
\hline
\end{tabular}

Hospital and Health Service, 2017a; Central Queensland University, n.d.) and the occupational therapy handbook (Occupational Therapy Clinical Education Program, 2018), encouraged students to work towards developing a collaborative relationship with their clinical educator. The Occupational Therapy Student Practice Placement Handbook specified that students were "to record feedback given by Clinical Educator and to actively work towards addressing this and implementing strategies accordingly" (Occupational Therapy Clinical Education Program, 2018, p. 9).

Contact with members of other health professions was encouraged to support student learning and was considered essential to support effective patient care. Students were instructed to "arrange to observe as many other professionals at work within your service, as you can learn a lot from other professions" (Darling Downs Hospital and Health Service, n.d.b, p. 12)

The Physiotherapy Student Orientation Manual stated:

[Students should] demonstrate an awareness of individual health worker's rolesphysiotherapist, social worker, occupational therapist, nurse, specialist doctors, speech therapists, and refer to them appropriately" (Darling Downs Hospital and Health Service, 2016, p. 7).

Eleven of the 13 documents described aspects of contact with a students' own and other professions, with references to respect for and communication with other professions and developing an understanding of professional roles through observation, liaison and interprofessional learning opportunities, such as tutorials. It was expected that students would demonstrate respect for members of their own profession by participating in professional activities, such as meetings and professional development, and showing willingness to present information to staff during in-services. The psychology manual highlighted the value of this contact with other professionals and provided 
WORDS IN ACTION

students with strategies to make connections, for example, the Psychology Fact Sheet Multidisciplinary Teams included:

\section{Where can I find more information?}

Ask!! Your colleagues are the best sources of information regarding their training and theoretical models. Conversations around multidisciplinary collaboration are best achieved when you consult with your particular team about their models, preferences, guidelines. Learning about other disciplines can only expand your ideas about "best practice" and lead to you becoming a more well-rounded clinician. (Psychology Clinical Education Program, n.d., p. 1)

Learning through working with patients was described in nine documents, with references to communicating with patients, respecting them and maintaining confidentiality, and partnering with patients through seeking consent and treatment planning.

\section{Acting supported by graded learning and service contribution}

The act theme described actions for gaining independence and autonomy in working with patients and recognition as a health professional. Documents described graded learning to support learning and student contribution to service delivery. Recognition as a health professional by professionals from other professions was also described. The psychology manual described the stages from being a beginning practitioner to competence and emphasised the need to balance student autonomy and dependency needs. The Social Work Evaluation (competency) document assessed that students had and obtained knowledge for effective practice and demonstrated the skills required to implement knowledge into practice (Central Queensland University, n.d.).

Documents encouraged students to advocate for the role of their profession within the multidisciplinary team and consult and coordinate with others in teams to work effectively in patients' care. Other references were made to student contact with referrers, discussing their planned treatment with other professionals and following up patient care.

Recognition of a member of a health profession can be supported by dress/uniform requirements for the profession or wearing a name badge identifying a person as a student member of the profession whilst in the placement workplace. Orientation documents referenced the importance of identifying as a member of the students' profession and representing this in a professional manner.

The way you dress has an impact on your clients, their family and friends, your peers and the general public. It is important to wear clothes that show you respect the people you work with and assists you to engage and build rapport with them. You are also representing the [name of health service] and so it is important that you look professional. It is expected that you wear appropriate professional dress for the hospital environment. ... Your student identification badge is to be worn at all times during the placement. (Darling Downs Hospital and Health Service, 2017b, p. 13) 
WORDS IN ACTION

The occupational therapy welcome email described how their profession valued student contribution to projects on placement:

[Name of health service] OTs value the opportunity to partner with students in the completion of a project to support our service delivery. (Darling Downs Hospital and Health Service, n.d.a, para. 9)

\section{Feeling supported by connectedness in the workplace}

The feeling category described workplace practices supporting students to connect with others in the workplace. The aim of the placement was to develop professional competence and achieve entry into the community of practice on placement. Documents made explicit reference to strategies to support learning and opportunities for connection with others while on placement. This is illustrated in the following quote:

Students are also encouraged to develop friendly working relationships with peers, supervisors and colleagues. (Darling Downs Hospital and Health Service, n.d.b, p. 11)

The health service commitment to clinical education was summed up in the psychology student manual:

The [name of health service] encourages education, and at all times there will be medical doctors undertaking specialty training and students on placement from various universities and discipline backgrounds, including medical students, nursing students and other allied health trainees. Health Service staff are familiar with having students on placement and your placement may be one of many, at any given time. (Darling Downs Hospital and Health Service, n.d.b, p. 9)

Some documents had a warm and welcoming flavour that enabled connectedness. An example of this style of communication in the documents was:

Welcome to Speech Pathology in the [name of health service]! ... This orientation package will provide much of the information needed for you to settle in and become adjusted to the way things operate within [the Health Service]. The information provided is not exhaustive, so please feel free to approach your Clinical Education Support Officer, [name] or your Clinical Educator with any further questions. Separate orientation information is available for each of the work areas.

We hope you enjoy your placement here and take away many new clinical skills and positive memories of your time with us. All the best for the coming weeks! (Darling Downs Hospital and Health Service, 2017b, p. 1)

In contrast to the quote above, a more professional tone was used for this quote from another profession:

Students are requested to contact the department by email or phone at least 2 weeks prior to arrival to discuss accommodation requirements and expectations of the clinical placement. (Darling Downs Hospital and Health Service, 2016, p. 2) 
WORDS IN ACTION

Some language in documents used inclusive pronouns, such as "we" or "us", in contrast to other documents that addressed students as "the student" or "you". With the aim of placement being to develop professional competence and support entry into the workplace community of practice, the documents made explicit reference to strategies to support learning and opportunities for socialisation available on placement:

Students are also encouraged to develop friendly working relationships with peers, supervisors and colleagues. (Darling Downs Hospital and Health Service, n.d.b, p. 1)

Social work students are provided with the opportunity to maximize their professional and interprofessional health learning whilst on placement by attending tutorials and other professional development. (Social Work and Welfare Clinical Education Program, n.d., para. 5)

For students entering a rural and regional health service for placement, orientation manuals provided information about the type of student accommodation available and opportunities for connection this provided. In the student welcome email, one profession shared photographs of accommodation and activities available in the regional towns supported by the health service. The welcome email for another profession provided a video link where previous students spoke about their rural placement experiences.

\section{Discussion}

This research adds to clinical education literature by providing insight into how clinical placement documents can contribute to students thinking, acting and feeling like a health professional, supporting identity development. All documents in this study implicitly or explicitly referred to thinking, acting and feeling like a professional.

With the aim of placement being to develop professional competence and achieve entry into the community of practice, learning to participate in workplace situations supports identity development (Billett, 2014; Mylrea et al., 2017). Workplaces provide opportunities to students to support their participation in learning and engagement in healthcare service delivery through development of autonomy and independence. The invitational qualities of physical and social situations offered to learners by the workplace are described as "affordances" (Billett \& Sweet, 2015). Documents in this study highlighted affordances for students, such as opportunities to interact with and learn from others in their profession and members of other professions, support for learning provided by clinical educators and the availability of accommodation. While the workplace affords students these opportunities, it is up to them how they respond to and engage with the opportunities.

Workplaces also impose expectations and norms on students that serve the interests of the workplace, other professions and patients (Billett, 2004). Expectations and insight into how the workplace intentionally regulates student participation are detailed in orientation and clinical education documents. In this study, orientation and student handbooks provided the first point of contact with the workplace, gave students information about affordances available to them and detailed how they could take up these affordances. 
WORDS IN ACTION

It is recommended that when clinical placement documents are written or reviewed, consideration is given to both the style of language and content (such as providing details of affordances and information to help students connect with and participate in workplace learning). This enables an approach that is welcoming and engaging rather than one that might be seen to be restrictive and exclude individual participation in workplace learning (Billett \& Sweet, 2015)

The generalisability of this study may be limited by the subjective interpretation of the researcher (Lingard, 2015; Workman, 2007). Given the documents examined have been sourced from one public health service, consideration of transferability of study findings to other organisational settings needs to be made with reference to clinical education policies, procedures and practices, and organisational culture and context.

\section{Conclusion}

Placement orientation and competency assessment documents can play a role in the development of professional identity for allied health students, helping them to think, act and feel like a health professional. Documents provide the first contact for students and share information about affordances available to them. They set expectations, support placement experiences and detail learning and competency outcomes. Clinical education documents have the potential to either draw students in to the workplace community or distance them through the language used, communication style and content. Therefore, to support student development of professional identity through transition into the workplace community, it is important to consider how placement expectations and information are communicated to students in organisational documents used for placement. Readers are invited to consider the applicability of findings to their placement context. Further research could be undertaken to explore how discourse and language are used in clinical placement documents to facilitate affordances as students enter the workplace.

\section{Acknowledgements}

This publication is part of Linda Furness's Doctor of Professional Studies at the University of Southern Queensland. The authors would like to thank the Toowoomba Hospital Foundation for Research Scholarship Funding (THF 2018 R1 01).

\section{References}

Billett, S. (2004). Workplace participatory practices: Conceptualising workplaces as learning environments. Journal of Workplace Learning, 16(6), 312-324. https:// doi.org/10.1108/13665620410550295

Billett, S. (2014). Learning in the circumstances of practice. International Journal of Lifelong Education, 33(5), 674-693. https://doi.org/10.1080/02601370.2014.908 425 
WORDS IN ACTION

Billett, S., \& Sweet, L. (2015). Participatory practices at work: Understanding and appraising healthcare students learning through workplace experiences. In J. C. Steven \& J. During (Eds.), Researching medical education (pp. 117-128). Wiley.

Bowen, G. A. (2009). Document analysis as a qualitative research method. Qualitative Research Journal, 9(2), 27-40. https://doi.org/10.3316/QRJ0902027

Bradshaw, C., Atkinson, S., \& Doody, O. (2017). Employing a qualitative description approach in health care research. Global Qualitative Nursing Research, 4. https:// doi.org/10.1177/2333393617742282

Braun, V., \& Clarke, V. (2006). Using thematic analysis in psychology. Qualitative Research in Psychology, 3(2), 77. https://doi.org/10.1191/1478088706qp063oa

Central Queensland University. (n.d.). Final field education report: SOWK13009_ Field Education 1. Author.

Cruess, R. L., \& Cruess, S. R. (2016). Professionalism and professional identity formation: The cognitive base. In R. L. Cruess, S. R. Cruess, \& Y. Steinert (Eds.), Teaching medical professionalism: Supporting the development of a professional identity (2nd ed., pp. 5-25). Cambridge University Press.

Cruess, R. L., Cruess, S. R., Boudreau, J. D., Snell, L., \& Steinert, Y. (2014). Reframing medical education to support professional identity formation. Academic Medicine, 89(11), 1446-1451. https://doi.org/10.1097/ ACM.0000000000000427

Cruess, R. L., Cruess, S. R., Boudreau, J. D., Snell, L., \& Steinert, Y. (2015a). Additional suggestions for facilitating professional identity formation [Comment in the article "In reply to Weissman"]. Academic Medicine, 90(6), 697-698. https://doi.org/10.1097/ACM.0000000000000727

Cruess, R. L., Cruess, S. R., Boudreau, J. D., Snell, L., \& Steinert, Y. (2015b). A schematic representation of the professional identity formation and socialization of medical students and residents: A guide for medical educators. Academic Medicine, 90(6), 718-725. https://doi.org/10.1097/ACM.0000000000000700

Dall'Alba, G. (2009). Learning professional ways of being: Ambiguities of becoming. Educational Philosophy and Theory, 41(1), 34-45. https://doi.org/10.1111/j.14695812.2008.00475.x

Darling Downs Hospital and Health Service. (n.d.a). Occupational therapy welcome email template. Queensland Government.

Darling Downs Hospital and Health Service. (n.d.b). Psychology student orientation guide. Queensland Government.

Darling Downs Hospital and Health Service. (2016). Toowoomba Physiotherapy Department: Student orientation manual. Queensland Government.

Darling Downs Hospital and Health Service. (2017a). Onboarding student orientation presentation [PowerPoint slides]. Queensland Government.

Darling Downs Hospital and Health Service. (2017b). Speech pathology student orientation manual. Queensland Government. 
WORDS IN ACTION

Frost, H. D., \& Regehr, G. (2013). "I AM a doctor": Negotiating the discourses of standardization and diversity in professional identity construction. Academic Medicine, 88(10), 1570-1577. https://doi.org/10.1097/ACM.0b013e3182a34b05

Furness, L., Tynan, A., \& Ostini, J. (2019). What supports allied health students to think, feel and act as a health professional in a rural setting? Perceptions of allied health staff. Australian Journal of Rural Health, 27(6), 489-496. https://doi. org/10.1111/ajr.12557

Furness, L., Tynan, A., \& Ostini, J. (2020). What students and new graduates perceive supports them to think, feel and act as a health professional in a rural setting. Australian Journal of Rural Health, 28(3), 263-270. https://doi. org/10.1111/ajr.12607

Hercelinskyj, G., Cruickshank, M., Brown, P., \& Phillips, B. (2014). Perceptions from the front line: Professional identity in mental health nursing. International Journal of Mental Health Nursing, 23(1), 24-32. https://doi.org/10.1111/ inm. 12001

Holden, M., Buck, E., Clark, M., Szauter, K., \& Trumble, J. (2012). Professional identity formation in medical education: The convergence of multiple domains. HEC Forum, 24(4), 245-255. https://doi.org/10.1007/s10730-012-9197-6.

Holden, M. D., Buck, E., Luk, J., Ambriz, F., Boisaubin, E. V., Clark, M. A., Mihalic, A., Sadler, J., Sapire, K., Spike, J., Vince, A., \& Dalrymple, J. L. (2015). Professional identity formation: Creating a longitudinal framework through time (transformation in medical education). Academic Medicine, 90(6), 761-767. https://doi.org/10.1097/ACM.0000000000000719

Jaye, C., \& Egan, T. (2006). Communities of clinical practice: Implications for health professional education. Focus on Health Professional Education: A Multi-disciplinary Journal, 8(2), 1-10.

Li, L. C., Grimshaw, J. M., Nielsen, C., Judd, M., Coyte, P. C., \& Graham, I. D. (2009). Evolution of Wenger's concept of community of practice. Implementation Science, 4, 1-8. https://doi.org/10.1186/1748-5908-4-11

Lingard, L. (2015). The art of limitations. Perspectives on Medical Education, 4(3), 136-137. https://doi.org/10.1007/s40037-015-0181-0

McBride, L.-J., Fitzgerald, C., Morrison, L., \& Hulcombe, J. (2015). Pre-entry student clinical placement demand: Can it be met? Australian Health Review, 39(5), 577-581. https://doi.org/10.1071/AH14156

Merton, R. K. (1957). Some preliminaries to a sociology of medical education. In R. K. Merton, G. G. Reader, \& P. L. Kendall (Eds.), The student-physician: Introductory studies in the sociology of medical education. A report of the Bureau of Applied Social Research of Columbia University (pp. 3-81). Harvard University Press.

Miles, M. B., \& Huberman, A. M. (1994). Qualitative data analysis: An expanded sourcebook. Sage. 
Miller, F. A., \& Alvarado, K. (2005). Incorporating documents into qualitative nursing research. Journal of Nursing Scholarship, 37(4), 348-353. https://doi. org/10.1111/j.1547-5069.2005.00060.x

Monrouxe, L., \& Poole, G. (2013). An onion? Conceptualising and researching identity. Medical Education, 47(4), 425-429. https://doi.org/10.1111/ medu. 12123

Mylrea, M. F., Gupta, T. S., \& Glass, B. D. (2017). Developing professional identity in undergraduate pharmacy students: A role for self-determination theory. Pharmacy, 5(2), 1-9. https://doi.org/10.3390/pharmacy5020016

Nicola-Richmond, K. M., Pepin, G., \& Larkin, H. (2016). Transformation from student to occupational therapist: Using the Delphi technique to identify the threshold concepts of occupational therapy. Australian Occupational Therapy Journal, 63(2), 95-104. https://doi.org/10.1111/1440-1630.12252

Occupational Therapy Clinical Education Program. (2018). Student practice placement handbook. Queensland Government.

O'Leary, Z. (2007). The essential guide to doing research. Sage.

Ó Lúanaigh, P. (2015). Becoming a professional: What is the influence of registered nurses on nursing students' learning in the clinical environment? Nurse Education in Practice, 15(6), 450-456. https://doi.org/10.1016/j.nepr.2015.04.005

Psychology Clinical Education Program. (n.d.). Fact Sheet 2.1: Multidisciplinary teams in Department of Health. Queensland Government.

Sharpless, J., Baldwin, N., Cook, R., Kofman, A., Morley-Fletcher, A., Slotkin, R., $\&$ Wald, H. S. (2015). The becoming: Students' reflections on the process of professional identity formation in medical education. Academic Medicine, 90(6), 713-717. https://doi.org/10.1097/ACM.0000000000000729

Social Work and Welfare Clinical Education Program. (n.d.). Social work welcome email template. Queensland Government.

The University of Queensland. (n.d.). Clinical Psychology Practicum Competencies

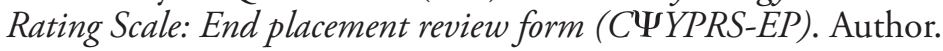

Vivekananda-Schmidt, P., Crossley, J., \& Murdoch-Eaton, D. (2015). A model of professional self-identity formation in student doctors and dentists: A mixed method study. BMC Medical Education, 15(83), 1-9. https://doi.org/10.1186/ s12909-015-0365-7

Wald, H. S. (2015). Professional identity (trans)formation in medical education: Reflection, relationship, resilience. Academic Medicine, 90(6), 701-706. https:// doi.org/10.1097/ACM.0000000000000731

Weaver, R., Peters, K., Koch, J., \& Wilson, I. (2011). "Part of the team": Professional identity and social exclusivity in medical students. Medical Education, 45(12), 1220-1229. https://doi.org/10.1111/j.1365-2923.2011.04046.x 


\section{WORDS IN ACTION}

Wilson, I., Cowin, L. S., Johnson, M., \& Young, H. (2013). Professional identity in medical students: Pedagogical challenges to medical education. Teaching and Learning in Medicine, 25(4), 369-373. https://doi.org/10.1080/10401334.2013.8 27968

Workman, B. (2007). "Casing the Joint": Explorations by the insider-researcher preparing for work-based projects. Journal of Workplace Learning, 19(3), 146-160. https://doi.org/10.1108/13665620710735620 